\title{
Reframing of Nuclear Safety Logic on the Basis of Resilience Engineering
}

\author{
Tohoku University, Masaharu Kitamura
}

\begin{abstract}
Public discussion on the future of nuclear energy depends crucially on how nuclear safety is established in the wake of the Fukushima Accident and how it is explained to the public. This issue cannot be addressed by simply explaining the technical measures that need to be introduced to enhance safety. How could an accident be whitewashed by simply dismissing it as an unexpected event? Why did the concerned parties fail to immediately take heed of the warnings given before the Fukushima Accident about the likelihood of tsunamis and station blackouts? The public rejection of nuclear power will remain unchanged unless such questions are properly addressed. This commentary explains that the logical backing provided by safety based on defense in depth as applied in the nuclear sector, which had been considered inherently adequate, has been undermined due to changes to the intended targets over time and efforts to adapt to changes involving the incorporation of new findings. In future discussions of nuclear safety logic, it is vital that the nuclear industry adapt to these changes effectively. This commentary also describes the significance of resilience engineering as a guiding methodology for dealing with the relevant changes.
\end{abstract}

\section{Introduction}

"Continued nuclear power generation is inconceivable after the calamity brought about by the Fukushima Accident." "The resumption of nuclear power generation cannot be approved without a guarantee of no accidents." Such opposition to nuclear power generation is voiced almost every day. However, there are also voices who argue in favor of continued or expanded operation of nuclear power plants by stating, for instance, that "Nuclear power plants need to be operated to a certain degree given the circumstances of tight energy and regional power supplies in Japan" and "Resumption is acceptable now that plant safety has been enhanced by the adoption of various safety measures." These conflicting opinions can be heard among citizens, experts, and politicians if we observe media coverage.

The most important cause of these clashes is almost certainly the inadequate response to serious safety concerns. Other problems related to nuclear power include issues concerning the final disposal siting for highly radioactive waste, the stagnation of the nuclear fuel cycle,

DOI : 10.15669/fukushimainsights.Vol.2.127

(C) 2021 Atomic Energy Society of Japan. All rights reserved.

Originally published in Journal of the Atomic Energy Society of Japan (ISSN 1882-2606), Vol. 54, No. 11, p. 721-726 (2012)

in Japanese. (Japanese version accepted: August 22, 2012) 
and the high costs involved in considering the possible effects of accidents. The biggest concern for the public is the perceived danger of nuclear power, which was reinforced by the Fukushima Accident. Kikkawa ${ }^{1)}$ rightly points out that "In the wake of the accident at the Fukushima Daiichi Nuclear Power Plant, Japan cannot operate nuclear power plants simply out of necessity. It is impossible for their operation to be resumed unless Japan faces up to the hazards involved by adopting measures to minimize such hazards while meeting energy needs."

In keeping with this view, nuclear experts should thoroughly examine and explain the reasoning for their claims about nuclear safety and the validity of such claims. Since June 2011, this journal has already presented explanations of the causes of the Fukushima Accident and discussions on measures that should be taken going forward. To the best of the author's knowledge, however, nuclear safety has not been discussed with respect to a logical system except for the contemporary opinion expressed by Morokuzu ${ }^{2)}$ in reference to the need for such a discussion. (After this commentary was submitted, the August 2012 issue of the Journal of the Atomic Energy Society of Japan published a commentary by Hiroshi Miyano et al. entitled "Prevent Recurrence of Nuclear Disaster (2): Reconstruction of Safety Logic Diagram of Nuclear System" [in Japanese]. Although the proposals made in these two commentaries differ, they share some commonalities in terms of their overall purposes.)

Regardless of who is right or wrong, the conflicting arguments mentioned earlier and any further discussion are irrelevant and pointless unless we question the logic behind the claims about nuclear safety and explanations of how nuclear safety is ensured (hereinafter referred to as "nuclear safety logic"). If the conventional nuclear safety logic is wrong, what aspects of it need modification? If it is not wrong, then why did it fail to prevent the Fukushima Accident? What types of modifications would significantly enhance safety? Further consideration must be given to these kinds of questions. Once answers have been obtained, it will also be necessary to consider how they can be clearly explained to the public. Future nuclear policies should no longer be discussed and decided in a broad sense along conventional lines involving the exclusive participation of nuclear experts (often sarcastically referred to as the "nuclear village"). Even before the Fukushima Accident, a wide range of people had advocated the adoption of trans-science, which calls for the involvement of citizens in addressing problems that arise between technologies and our society rather than just leaving this task to a group of experts $^{3,4)}$. This participatory policymaking took on even greater importance after the accident. Given these circumstances, it goes without saying that explanations of nuclear safety are important and necessary.

As someone involved in the nuclear sector, the author felt at loss about how to react to the inconvenience and pain experienced by members of the local community in the wake of the serious accident that occurred in Fukushima. All that came to mind were words of apology and remorse. However, regardless of the type of scenario that Japan decides to choose, a reexamination of the nuclear safety logic and an adequate explanation of this to the public are tasks that cannot be shirked. Nuclear experts have a duty to make a sincere effort to learn lessons from the Fukushima Accident. With this in mind, the discussion proceeds as follows.

\section{Nuclear Safety Logic}

We need to start by considering how the questions raised in the previous chapter should be answered. What efforts had the nuclear sector stakeholders, who eventually failed to prevent the Fukushima Accident, actually made? 
With respect to this question, it should be noted that the existing Act on the Regulation of Nuclear Source Material, Nuclear Fuel Material and Reactors attempts to prevent accidents through just three approaches: (1) prevention of abnormal operation; (2) prevention of escalation; and (3) mitigation of impact. The majority of nuclear experts would share the view that the five levels of defense in depth advocated by the International Atomic Energy Agency (IAEA) additionally try to implement measures for dealing with severe accidents and emergency preparedness ${ }^{5)}$. A wide range of comments highlight the limitations of the three approaches mentioned above.

However, the nuclear safety logic was not necessarily created in this way from the beginning. Nuclear safety experts at least knew that the nuclear safety logic was created to provide defense in depth with many more levels of protection ${ }^{6}$. The quoted document was written by a former member and chair of the Nuclear Safety Commission. This defense in depth adopts a total of seven levels of defense: (1) siting; (2) suppression of abnormal events; (3) early detection and response to abnormal events; (4) mitigation of impact; (5) accident management; (6) isolation to minimize any interaction between the facility and society as a whole; and (7) emergency preparedness. Leaving aside the details, it is clear that Japanese guidelines at least ensure a level of safety that is comparable to that provided by the international guidelines advocated by the IAEA. Simply put, the nuclear safety logic that was previously known in Japan already considered a broader range of aspects than just the prevention of abnormal operation, the prevention of escalation, and the mitigation of impact.

Rather than asking why nuclear regulations and plant operations in Japan have been backed by defective safety logic, the question we should be asking is why the original nuclear safety logic with seven levels of defense has atrophied and degenerated into one with just three levels of defense in practice. If the only known logic was, in principle, defective and consequently compromised safety, modifications to this logic could enhance safety. However, the truth is that the atrophied and degenerated version of the original logic had already been adopted. Given this, it is necessary to identify and eliminate the causes of this change for the worse. The top priority is to implement measures to prevent any failure to detect signs of deterioration or take the necessary actions.

A commonly encountered explanation for this deterioration of safety is the allegedly evil nature of stakeholders in the nuclear industry based on the criticism that "Blinded by their own interests, members of the nuclear village have neglected safety." This may not be entirely off the mark, but our intellectual efforts should not stop there. It is human nature to simplify an issue to minimize the cognitive burden associated with handling it. Furthermore, people tend to persist with their view once they have made a judgment. J. Reason, an internationally respected authority on the human and organizational impact on safety, warns of this tendency, which he describes as the "principle of minimum effort" or the "principle of supervisory convenience $^{7)}$." An obsession with assuming that an accident was caused by someone's mistake or negligence is also identified as a problem in the field of human factor safety engineering. This issue requires much deeper consideration.

\section{Factors Behind the Undermined Nuclear Safety Logic}

As stated in the previous chapter, investigating the causes of an accident based on a simplified assumption often ends up in a partial understanding of the reality of the situation. Nuclear experts are widely criticized for having stopped thinking in relation to their assumptions concerning earthquakes and tsunamis. The author also shared such a view ${ }^{8)}$, but only in the 
limited context required to preclude any excuses by engineers that they did not anticipate certain events. In terms of this commentary, the essential task is to develop a big picture of the way in which the nuclear safety logic atrophied and degenerated.

A standardized criticism of nuclear experts is often encountered. The press tends to adhere to a narrative in which safety was undermined when members of the nuclear village fell into a trap of their own making by believing their own myth of safety. In Chapter 9 of its report, the Independent Investigation Commission on the Fukushima Daiichi Nuclear Accident expressed its own view on the social background to the myth of safety. In a general sense, this myth of safety conjures an image of complacent groups of people who blindly believe in nuclear safety and neglect to take adequate safety measures. However, such a perception only presents one side of the story. This view is unerringly criticized by a commentary ${ }^{9)}$ published in this journal.

"After the Fukushima Accident, some experts criticized the nuclear industry by saying that it had been beguiling citizens with the myth of safety. However, such comments do not necessarily hold water. For instance, the Kansai Electric Power Company substantially corrected the statement published in its public relations journal claiming that 'accidents never happen' when an ECCS was prompted to operate during the accident at its Mihama Nuclear Power Plant in 1991. The 2000 issue of the White Papers on Nuclear Safety published by the Nuclear Safety Commission clearly stated that they would break away from the myth of safety."

Based on his practical experience, the author did not believe that experts simply assumed that no accidents would take place. In fact, the author felt uncomfortable with the various clichés that were propagated whenever nuclear power plants experienced trouble, such as that the myth of safety was dead. It is wrong to assume that blind faith in the myth of safety meant that we could not prevent the accident. Completely different mechanisms should be considered as possible causes.

Let us instead focus on the following statement in a report by the Independent Investigation Commission: "During the study, senior government officials responsible for nuclear safety and the former management of the Tokyo Electric Power Company made the unanimous statement that although they were aware that the safety measures were inadequate, they believed that nothing would change even if they went against the prevailing opinion" (p. 7). We need to give careful consideration to this statement suggesting that many stakeholders remained silent even though they were all aware of the problem.

The author did not foresee the hazard posed by the last major tsunami. Feeling ashamed of his incompetence, he presented some possible measures aimed at preventing a repeat of this failure to predict important events ${ }^{8)}$. As long as their views are sincere, we need to introduce other measures to keep people from remaining quiet about problems despite being aware of them. The paper published by Kinoshita ${ }^{9)}$ classifies unanticipated events into five categories, and the author employs a similar classification for this commentary as shown in Table 1. According to this classification, none of the nuclear accidents and problems experienced in the past could be considered unanticipated in a strict sense. Arguably, proper measures could have been taken if enough attention had been paid to errors made by the evaluators.

The author is not claiming that all events can be anticipated. In principle, the possibility of unanticipated events cannot be denied, but unanticipated events experienced in the past were actually excluded from predictive efforts. The number of unanticipated events could actually be considerably reduced, thereby helping to enhance safety. To do this, we need to avoid the imprudent (or intentional) exclusion of any event from predictive efforts. Instead, we should always ask if anything could be done if the event were to occur and take measures accordingly if it does take place. 
Table 1 Classification of possible unanticipated events and judgment errors by evaluators

\begin{tabular}{|c|c|c|c|}
\hline Event category & Event characteristics & $\begin{array}{l}\text { Factors related to judgmental errors by } \\
\text { evaluators }\end{array}$ & Typical example \\
\hline $\begin{array}{l}\text { (1) Extremely } \\
\text { unlikely event }\end{array}$ & The event is objectively unlikely. & $\begin{array}{l}\text { The probability can be deemed virtually } \\
\text { nil. However, it is not acceptable for it to } \\
\text { be omitted from an impact assessment. }\end{array}$ & Meteorite impact \\
\hline $\begin{array}{l}\text { (2) Simultaneous } \\
\text { occurrence of } \\
\text { multiple failures }\end{array}$ & $\begin{array}{l}\text { The combination of events is } \\
\text { unlikely if considered as an } \\
\text { independent event. }\end{array}$ & $\begin{array}{l}\text { This is unacceptable without } \\
\text { consideration being given to common } \\
\text { factors that may cause damage to } \\
\text { multiple pieces of equipment and the loss } \\
\text { of multiple functions. }\end{array}$ & $\begin{array}{l}\text { Simultaneous functional } \\
\text { loss of redundant power } \\
\text { supplies and multiple } \\
\text { cooling systems like the } \\
\text { one that led to the } \\
\text { Fukushima accident }\end{array}$ \\
\hline $\begin{array}{l}\text { (3) Controversy } \\
\text { among experts } \\
\text { (scientific } \\
\text { community) }\end{array}$ & $\begin{array}{l}\text { The majority deems the event } \\
\text { unlikely, while a minority thinks } \\
\text { it is likely. }\end{array}$ & $\begin{array}{l}\text { A decision being taken by the majority } \\
\text { without examining the reasoning of the } \\
\text { minority. }\end{array}$ & $\begin{array}{l}\text { Judgment error } \\
\text { concerning the presence } \\
\text { of active faults and their } \\
\text { possible interactions }\end{array}$ \\
\hline $\begin{array}{l}\text { (4) Earthquakes, } \\
\text { tsunamis, and other } \\
\text { natural disasters }\end{array}$ & $\begin{array}{l}\text { The probability is not negligible, } \\
\text { but the timing is highly uncertain. }\end{array}$ & $\begin{array}{l}\text { An incorrect interpretation of uncertain } \\
\text { timing meaning that it is not likely in the } \\
\text { near future. }\end{array}$ & $\begin{array}{l}\text { Inadequate } \\
\text { consideration of a major } \\
\text { tsunami that takes place } \\
\text { at an interval of XX } \\
\text { years (XX years since } \\
\text { the last one) }\end{array}$ \\
\hline $\begin{array}{l}\text { (5) Events that also } \\
\text { require non-nuclear } \\
\text { expertise }\end{array}$ & $\begin{array}{l}\text { The probability is not negligible, } \\
\text { but there is no precedent for such } \\
\text { an event. }\end{array}$ & $\begin{array}{l}\text { The event scenario is overlooked due to } \\
\text { inadequate expertise and a failure to } \\
\text { recognize the relevant information. }\end{array}$ & $\begin{array}{l}\text { Damaged thermometer } \\
\text { casing at the Monju } \\
\text { reactor }\end{array}$ \\
\hline $\begin{array}{l}\text { (6) Human and } \\
\text { mechanical } \\
\text { interactions }\end{array}$ & $\begin{array}{l}\text { The event scenario is } \\
\text { complicated by human and } \\
\text { mechanical interactions. }\end{array}$ & $\begin{array}{l}\text { Unduly inoperative equipment and } \\
\text { difficulty in reading instruments. }\end{array}$ & $\begin{array}{l}\text { Three Mile Island } \\
\text { accident }\end{array}$ \\
\hline $\begin{array}{l}\text { (7) Organizational } \\
\text { factors }\end{array}$ & $\begin{array}{l}\text { Multiple factors associated with } \\
\text { undermining the safety culture of } \\
\text { the overall organization }\end{array}$ & $\begin{array}{l}\text { A scenario of inadequacy that is usually } \\
\text { unlikely in a normal organization is } \\
\text { overlooked. }\end{array}$ & $\begin{array}{l}\text { Chernobyl accident, } \\
\text { JCO accident }\end{array}$ \\
\hline
\end{tabular}

Safety is clearly undermined if an increasing number of events are excluded from predictive efforts. Five or seven levels of protection in defense in depth were reduced to just three levels in practice, thereby leading to an atrophied nuclear safety logic. In addition to the neglect caused by the errors mentioned in Table 1, many events obviously tend to be excluded from predictive efforts due to advances in science and new findings gained along the way. New findings on earthquakes and tsunamis have been continuously acquired ever since safety reviews were first conducted during the construction of the Fukushima Daiichi Nuclear Power Plant and other nuclear power plants. It is widely known that the risks of tsunamis and station blackouts were identified well in advance (e.g., in reports published by the Independent Investigation Commission and the National Diet of Japan Fukushima Nuclear Accident Independent Investigation Commission). These new findings and identified issues could have served as important warnings.

Put another way, the fundamental factor behind the accident was inadequate sensitivity to alerts among utilities, regulators, and their organizations. As a reason for this, a number of people have identified an aversion to the increased costs associated with any changes. The report by the Independent Investigation Commission mentioned earlier also states the following: "The aforementioned former managing director confided that directors were evaluated based on their performance in relation to reducing costs in line with the slogan set by former President Araki to become an ordinary company, which undermined safety" (p. 319). Combined with the earlier quote, the scenario indicating that concerns over increased costs were the main reason seems convincing. However, even if this remark was genuine, the investigation into the accident should, according to widely known practices, go beyond this convincing scenario to examine the secondary story behind it ${ }^{10}$. Would these concerns over rising costs 
keep people from speaking up if a highly realistic tsunami alert was issued?

In practice, such an alert for a likely tsunami may have been excluded from the predictive efforts based on its classification in Table 1 under "(4) Earthquakes, tsunamis, and other natural disasters" and the assumed "(3) Controversy among experts (scientific community)." Most probably, the risk of undermined safety may in reality have been overlooked in light of the "(2) Simultaneous occurrence of multiple failures." It is highly likely that, behind the scenes, there was a vague resistance to any changes. The source of this resistance can be traced back to the principle of minimum effort, as quoted in Chapter II. It is quite conceivable that people dealing with an enormous nuclear power plant tend to feel that they do not need to respond to every single alert without sufficient evidence or that safety can be maintained by the robust construction of the plant without any improvements or changes. In other words, the root cause is the static assumption that, once a certain degree of safety has been achieved with a target model, safety can be maintained by proper maintenance and the prevention of human error.

Precisely for that reason, the prevention of another accident like the one in Fukushima and the enhancement of safety at nuclear power facilities should be fundamentally guided by efforts to enhance sensitivity to alerts, avoid exclusions from predictive efforts, and overcome resistance to changes. However, we cannot expect such effects to be made if these basic guidelines are simply treated as a philosophy. A tangible methodology is needed to translate the guidelines into realistic and functional policies within the organization and to develop the necessary system. The resilience engineering described in the next chapter is expected to play an important role as the required methodology.

\section{Ideal Nuclear Safety Logic and Resilience Engineering}

Based on the above discussion, it is reasonable to ascribe the Fukushima Accident to the mindset of nuclear experts who neglected the need for changes and excluded various events from predictive efforts. Resilience engineering lies diametrically opposite such a mindset ${ }^{11,12}$. This methodology prompts us to consider safety based on the basic understanding that any system and environment undergoes changes and that hazards can affect us at any time. For illustrative purposes, it can be compared to the guidelines followed by the captain of a sailing boat navigating a sea full of islands and treacherous reefs. Leaving a more detailed explanation to another paper ${ }^{13)}$, this commentary only presents an overview of resilience engineering.

Resilience engineering is a methodology that has been gradually developed by western researchers on safety as well as researchers and practitioners of human factors. Conventional studies on safety and human factors assumed that the nature of target systems remained constant over time. Human operators and pilots were regarded as error factors. Earlier studies sought to eliminate such errors, but the limitations of this approach gradually became apparent, and human factors were also recognized as potential sources of success. This awareness prompted the rapid development of resilience engineering from around $2004^{11,12}$.

The basic stance of resilience engineering can be summarized as follows.

A) Systems (nuclear power plants and operating organizations in relation to this commentary) and environments (natural and social) experience constantly dynamic changes. They may not be considered as unchanged.

B) System operators must always have a constant sense of unease and adapt to changes as necessary.

C) A response should be taken as soon as possible and appropriate in the event of any 
changes or external disturbances that could affect the systems.

D) System operations should be maintained by avoiding a critical catastrophe even if the expected function cannot be maintained due to a major change or an external disturbance. In such an event, flexible operations should be pursued without insisting on the initial goals.

E) System operators should be regarded not only as potential sources of errors, but also as potential sources of outstanding success.

This framework strikes a contrast with the conventional approach to safety, in which static and constant conditions are considered desirable. Such a framework is clearly more practical considering the degree of difficulty involved in dealing with the way the Fukushima Accident unfolded. The following measures need to be implemented for all systems to satisfy the requirements.

(a) Four functions must be ensured: (1) response to ascertain what needs to be done in the given situation; (2) conscious monitoring of matters that require attention; (3) anticipation of possible hazards; and (4) learning lessons from events that have been experienced previously.

(b) The required resources must be deployed to support these functions (e.g., personnel, equipment and devices, drawings, procedural manuals, other reference materials, and funds).

(c) The allocation of resources within the system must be dynamically optimized according to the prevailing conditions.

(d) Ideally, these functions (especially monitoring and anticipation) should be applied in a proactive manner, not a reactive manner.

(e) Importantly, lessons should be learned not only from failures, but also from successes and best practices.

Bearing in mind what happened during the Fukushima Accident, it should be clear that these specific measures are considerably more rational than those required by conventional nuclear safety logic. In addition to the four key functions described in (a) above, complementary requirements are provided in (b) through (d). These functions and requirements are flexibly applied according to the situation without any predefined order. Figure 1 provides a schematic illustration of resilience engineering.

For example, the following strategy could be adopted in the aftermath of a major earthquake.

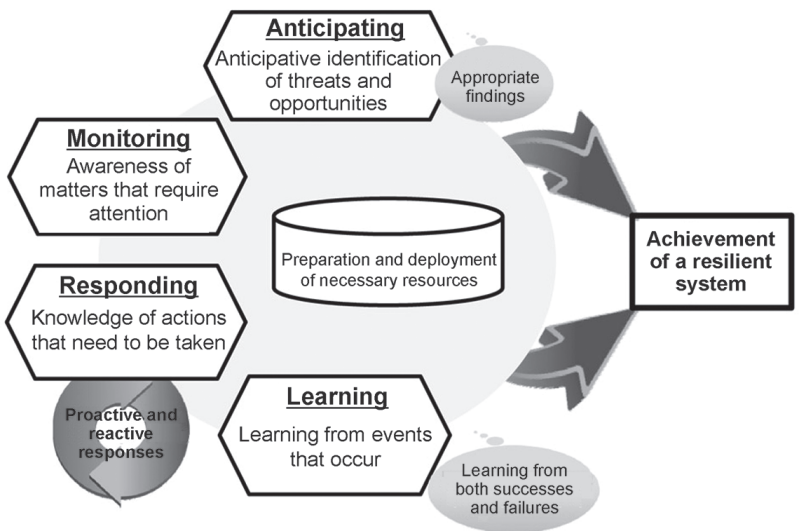

Figure 1 Four key functions of resilience engineering and complementary requirements 
(1) Respond to immediate needs by mobilizing the necessary resources.

(2) This response should be combined with careful monitoring to alert those in charge of the response.

(3) Make arrangements for the necessary resources in advance.

(4) Change the strategy as necessary after implementing response measures prepared in advance of the emergence of a threat.

(5) Anticipate further likely threats and notify the person in charge of management of the necessary measures.

(6) Once the emergency has been dealt with, compile the findings and provide input data to enable lessons to be learnt from the emergency.

During routine operations without any external disturbances, the following strategy could be taken.

(1) Always utilize the anticipation function to analyze the probability of systemic or environmental changes as well as any external warning data.

(2) When doing this, duly refer to the learning data gained from past events.

(3) If a threat is anticipated, enable the monitoring function and check the necessary resources for implementing a response. Modify the deployment of resources as necessary.

(4) If the threat does not materialize, return to anticipation mode and learn from the anticipation results.

In this way, system operations based on resilience engineering ensure that one or all key functions are always activated. This practice precludes the exclusion of certain events from predictive efforts as well as reduced sensitivity to alerts. Therefore, it can be claimed in a structured manner that systems (nuclear power plants in this context) can be made much safer. Resilience engineering clearly offers a more rational approach to achieving safety as it recognizes constant changes in systems and environments.

\section{Dialogue with Citizens as a Prerequisite}

Let us suppose that safety can be enhanced in the manner described in the previous chapter. However, nuclear power generation cannot be continued in today's society without first gaining public support by providing citizens with an explanation of the facts. In the past, safety was based on the atrophied nuclear safety logic through the provision of three levels of protection. A typical response to any criticism tended to be as follows: "The assumption of such an extreme event (a massive earthquake or damage to a primary containment vessel) is unrealistic. Please be assured that it will never happen." This kind of explanation has obviously lost its validity since the Fukushima Accident.

Even before the Fukushima Accident, though, we should have taken heed of the five levels of protection advocated by the IAEA or the seven levels of protection mentioned earlier. An appropriate explanation would have been something like the following: "We believe that such an event will not take place. However, we would not let any such event escalate into an accident. We are prepared to deal with such an event." Going even further, an explanation should have been provided with respect to the multiple levels of protection. Let us take the following question as an example: "What should be done if this event were to escalate into an accident for some reason?" Possible responses include "The necessary level of water would still be ensured for the core even in those circumstances" and "A hydrogen explosion can be avoided even if the water level cannot be ensured." In fact, such preparedness forms the essence of defense in depth and resilience engineering. Blind adherence to conventional explanations is not 
acceptable. To move in the right direction, we should seek public understanding by adding explanations such as the following: "We are always prepared and trained to respond swiftly to any abnormal events" and "We will adequately respond to all alerts."

On a related note, let us consider how to respond to a criticism that is often heard with respect to the controversy over whether to resume the operation of nuclear power plants: "Resumption is unacceptable when not even the tide embankments and quakeproof administrative buildings have been constructed yet." If this sort of claim is accepted, we will face opposition to every attempt to introduce new safety measures, with people saying: "The fact that the new measures have not been carried out yet makes the existing system dangerous and thus unacceptable." Naturally, discussions concerning safety cannot be conducted in a binary manner where matters are simply labeled as either black or white. An explanation of the nuclear safety logic through defense in depth requires much greater efforts than the conventional approach of explaining matters away by saying: "Such an extreme event will never happen." Nonetheless, experts have a duty to continue making the efforts necessary to consistently explain the nuclear safety logic that combines defense in depth with flexible responses to changes with the aim of reducing the likelihood of unanticipated events. Explanations of safety based on resilience engineering offer a significant leap forward in terms of fulfilling our professional duties.

\section{Conclusions}

This commentary sorted out various issues related to reframing nuclear safety logic and the significance of adopting the perspective of resilience engineering. Regardless of the outcome of discussions over the phasing out of nuclear energy, these issues need to be sorted out and discussions need to be carried out in a logical manner. This commentary points out that the conventional logic used in support of nuclear energy was not mistaken in essence, but it demonstrated that the failure to prevent the Fukushima Accident resulted from tunnel vision and the exclusion of certain events from predictive efforts while the logic was applied to actual nuclear power plants. As a possible solution to this problem, the methodology of resilience engineering was described as a framework for measures designed to enhance safety. Nuclear experts should share a common understanding of the significance of studies on safety based on resilience engineering and the specific measures that are necessary. They are also expected to communicate such information to the wider society.

\section{References}

1) Takeo Kikkawa: Realistic Ways to Unwind Nuclear Power Plants [in Japanese], Journal of the Atomic Energy Society of Japan, 54 (1), 22-26 (2012).

2) Muneo Morokuzu: High Time to Deepen the Safety Philosophy of Defense in Depth [in Japanese], Journal of the Atomic Energy Society of Japan, 53 (12), 794-795 (2011).

3) Tadashi Kobayashi (ed.): Science and Technology in the Public Sphere [in Japanese], Tamagawa University Press (2002).

4) Ekou Yagi: Designing a Venue for Dialogue [in Japanese], Osaka University Press (2009).

5) Satoru Tanaka: Toward Risk Governance [in Japanese], Applied Energy, 35 (1), 4 (2012).

6) Kazuo Sato: Logic of Nuclear Safety [in Japanese], Nikkan Kogyo Shimbun (2006).

7) James Reason: The Human Contribution, Ashgate Publ. (2008).

8) Masaharu Kitamura: Lessons Learned from the Fukushima Daiichi Disaster [in Japanese], Journal of the Atomic Energy Society of Japan, 53 (6), 406-408 (2011).

9) Tomio Kinoshita: The Disaster by the Fukushima Nuclear Power Plants and the Risk Science [in 


\section{INSIGHTS CONCERNING THE FUKUSHIMA DAIICHI NUCLEAR ACCIDENT Vol. 2}

Japanese], Journal of the Atomic Energy Society of Japan, 53 (7), 465-472 (2011).

10) D.D. Woods and R.I. Clark: Nine Steps to Move Forward from Error, Cognition, Technology \& Work, 4: 137-144 (2002).

11) E. Hollnagel, D.D. Woods, and N. Leveson (eds.): Resilience Engineering: Concepts and Precepts, Ashgate (2006).

12) E. Hollnagel, J. Paries, D.D. Woods, and J. Wreathall: Resilience Engineering in Practice, Ashgate Publ. (2011).

13) Masaharu Kitamura: Application of Resilience Engineering to Improvement of Industrial Safety [in Japanese], Human Interface, 14 (2), 5-10 (2012). 